\title{
The Telecommunications Industry and ECONOMIC GRowth: How the Market StruCture MatTers
}

\author{
Vahagn Jerbashian*
}

September 2, 2015

\begin{abstract}
This paper presents an endogenous growth model where the telecommunications industry is the engine of growth. In such a framework, it analyzes how the market structure of the telecommunications industry can matter for its contribution to long-run growth. It shows that policies which increase the number of firms and/or toughen competition imply higher innovative effort in the telecommunications industry and strengthen its contribution. Modeling entry into the telecommunications industry, this paper also shows that the entry either stops after a number of firms have entered or continues permanently. In the long-run, it is socially optimal to have permanent entry. This can necessitate subsidies to entry into the telecommunications industry.
\end{abstract}

Keywords: Telecommunications Industry; Market Structure; Economic Growth JEL classification: O41; O25; L10

\footnotetext{
*Departament de Teoria Econòmica and CREB, Universitat de Barcelona, and CERGE-EI. Correspondence address: Avenue Diagonal 696, 08034 Barcelona, Spain. E-mail: vahagn.jerbashian@ub.edu. Phone: +34934034890.

CERGE-EI is a joint workplace of the Center for Economic Research and Graduate Education, Charles University in Prague, and the Economics Institute of Academy of Sciences of the Czech Republic.
} 


\section{Introduction}

A vast empirical literature suggests that the telecommunications industry makes a significant contribution to economic growth (e.g., Röller and Waverman, 2001). ${ }^{1}$ According to the theory and many empirical studies, this contribution can depend on the market structure of the telecommunications industry since the market structure can affect, for example, competitive pressure in the industry and therefore the incentives to innovate (e.g., Blundell et al., 1999; Vives, 2008). The market structure can also determine the inefficiencies stemming from the market power of telecommunication firms (telecom firms). These inefficiencies can alter the demand for the goods produced in the telecommunications industry, which can also affect its contribution to economic growth.

This type of inefficiencies have motivated, for instance, the Telecommunications Act of 1996 in the US and Directives 90/388/EEC, 96/19/EEC, 2002/22/EC, and $2002 / 58 / \mathrm{EC}$ in the EU. These policies propose and have motivated already changes in the market structure of the telecommunications industry in the US and EU countries. Recently, the wave of privatization of state owned telecom firms and the entry of new firms into the telecommunications industry has been the norm almost everywhere. As a result, telecommunications markets have become less concentrated commonly featuring more than a handful of big firms. These policies aim also at promoting the demand for telecommunications and innovation in the telecommunications industry. Policy makers motivate the promotion of the demand, for instance, by the external benefits from the use of telecommunications.

This paper models the telecommunications industry as the engine of economic growth in a general equilibrium framework. It assumes that telecom firms have market power and models intra-firm R\&D that improves the productivity of telecom firms (or the quality of telecommunications goods; e.g., the discovery and application of digital technologies). The theoretical framework of this paper also allows the telecom firms to engage in R\&D partnerships and cross-licensing activities. The significance of such partnerships and activities is largely documented for the telecommunications industry and other high-tech industries (see, for instance, Hagedoorn, 1993, 2002). ${ }^{2}$ According to anecdotal and empirical evidence it can significantly am-

\footnotetext{
${ }^{1}$ See also Oulton (2012) for a growth accounting exercise for information and communication technologies, which include telecommunications.

${ }^{2}$ The telecom firms' final outputs are, for instance, telephone calls and the internet. Although part of the innovation/R\&D for the telecommunications industry may not take place in this industry per se, in this paper the $\mathrm{R} \& \mathrm{D}$ process is modeled within telecom firms and the licensing activities are modeled across these firms. As long as innovation is paid its fair price, these assumptions do not drive the results of this paper.
} 
plify the innovation in such industries (see, for instance, Grindley and Teece, 1997; Belderbos et al., 2004).

In such a framework, this paper analyzes how the market structure of the telecommunications industry can affect its contribution to growth, while focusing on a symmetric equilibrium and balanced growth path analysis. ${ }^{3}$ Given that the market structure matters, the type of competition in the telecommunications industry (i.e., Cournot or Bertrand) can also play a role. Therefore, in addition, this paper suggests a link between economic growth and the type of competition in the telecommunications industry.

In line with the network economics literature (e.g., Gandal, 1995), this paper incorporates (direct) network externalities which increase the value of using telecommunications (telecom goods) with the level of adoption and use of telecommunications. ${ }^{4}$ In light of productivity improvements in telecom goods production, however, this paper replaces the level of adoption and use by the effective level of adoption and use, which seems to be novel at least in the aggregate level studies related to telecommunications. ${ }^{5}$ The intuition for such replacement is as follows: both the number of users and, for instance, the fault rate of lines, can affect the network externalities.

The theoretical results suggest that policies which increase the number of firms promote innovative effort in the telecommunications industry. Therefore, such policies increase the contribution of this industry to long-run growth. The driver behind this result are the relative price distortions. These distortions stem from the market power of telecom firms and increase the relative price of $R \& D$ inputs of telecom firms. Increasing the number of telecom firms increases competitive pressure and reduces relative price distortions, which motives higher investments in R\&D. The same result holds if competition type changes and becomes tougher (Bertrand vs. Cournot). The telecommunications industry also contributes more to long-run growth if network externalities are stronger.

Further, I consider the case when entry into the telecommunications industry is deregulated and endogenize entry into the telecommunications industry assuming that it entails endogenous sunk costs. These entry costs represent the capital investments of entrant telecom firms.

The results suggest that, depending on the economy, the entry either stops after

\footnotetext{
${ }^{3}$ See Bourreau and Doğan (2001) for a discussion of a relationship between regulation and innovation in the telecommunications industry.

${ }^{4}$ The existence of such externalities, although seems to be intuitive, does not have universal empirical support (e.g., see Röller and Waverman, 2001; Stiroh, 2003).

${ }^{5}$ To my best knowledge this is novel also for micro level studies related to telecommunications.
} 
some number of firms have entered or it continues forever. In the first case, the number of firms in the economy will be always finite, while in the second case it grows permanently. The drivers of this result are the investments in innovation for productivity improvement, which are fixed costs. The entry of firms erodes the revenues per firm, and these costs can be so high that the new entrant would have negative profits. Although, the case when the number of firms is finite in the long-run seems to be more plausible, it seems hard to rule out the case when it grows permanently. In turn, according to the results, in the social optimum (the Social Planner's optimal choice) there is permanent entry in the long-run. This can necessitate subsidies to the entry into the telecommunications industry.

The result that more intensive competition, because of entry into the telecommunications industry, promotes innovation and growth is consistent with empirical findings of Boylaud and Nicoletti (2001), Li and Xu (2004) and Paleologos and Polemis (2013). It is also consistent with more aggregate-level empirical findings of Blundell et al. (1999), Griffith et al. (2010), and Barone and Cingano (2011). ${ }^{6}$

This paper is related to studies which suggest how economic growth can be affected by imperfect competition in an industry where the firms engage in intra-firm R\&D and to studies which analyze the impact of information and communication technologies on growth (e.g., Smulders and van de Klundert, 1995; Venturini, 2007; Vourvachaki, 2009; Jerbashian, 2014). It contributes to these studies by showing how the continuous entry of firms can affect the intra-firm $R \& D$ process when there is knowledge licensing. It also contributes by showing that depending on the economy the entry of firms either stops after a finite number of firms have entered or continues permanently.

This paper is also closely related to the literature which suggests a positive impact of telecommunications on the aggregate economy (e.g., Röller and Waverman, 2001; Koutroumpis, 2009; Czernich et al., 2011; Paleologos and Polemis, 2013). It contributes to this literature by showing how the market structure of the telecommunications industry and the type of competition in that industry can affect the contribution of the telecommunications industry to long-run growth. It also suggests the market structure of the telecommunications industry that is socially optimal in the long-run, which seems to be an open question in the literature (see Röller and Waverman, 2001).

The model presented in this paper is a general endogenous growth model (for similar models see Romer, 1990; van de Klundert and Smulders, 1997; Minniti, 2010).

\footnotetext{
${ }^{6}$ The empirical debate about the relationship between competition and innovation seems far from being settled. For example, in contrast to these papers, Aghion et al. (2005) find that the relationship has an inverted-U shape, while Hashmi (2013) finds a mildly negative relationship.
} 
The adoption of such a model involves trade-offs. This model is well suited for the purpose of this paper since it allows explicit accounting for the channels through which the telecommunications industry and its market structure can affect the aggregate performance and long-run growth. On the other hand, however, this model abstracts from many of the complex details of the telecommunications industry. For example, it abstracts from market interactions at platform level (e.g., broadband vs. fixed line telephony) as well as interactions at platform-service level (e.g., broadband and television services). It does not capture product-level differences (e.g., cable and broadband) and differences in the demand for telecommunications (e.g., small vs. large firms). It also abstracts from state ownership of telecom firms as can be observed in some countries. Admittedly, this limits the sharpness of its inference for the telecommunications industry and policy recommendations.

From another perspective, this general model can have other applications as well. The only part of the model that might be hard to justify for other industries is the externalities associated with the use of telecommunications. For non-high-tech industries it can also be hard to justify the intra-firm R\&D process and knowledge (patent) licensing.

The next section presents the model and offers the optimal rules. Section 3 analyzes the features of dynamic equilibrium. It also offers the socially optimal allocations, compares these with the decentralized equilibrium allocations and suggests some comparative statics. Section 4 concludes. Proofs of propositions offered in the text are available in online appendices of this paper.

\section{The Model}

\section{$2.1 \quad$ Households}

The economy is populated by a continuum of identical and infinitely lived households of mass one. The representative household is endowed with a fixed amount of labor $(L)$. It inelastically supplies the labor to firms which produce homogenous final goods and to telecom firms. The household has a CIES instantaneous utility function with an intertemporal substitution parameter $1 / \theta$ and discounts the future streams of utility with rate $\rho(\theta, \rho>0)$. The utility gains are from the consumption of amount $C$ of final goods. The lifetime utility of the household is

$$
U=\int_{0}^{+\infty} \frac{C_{t}^{1-\theta}-1}{1-\theta} \exp (-\rho t) d t .
$$


The household finances its expenses through labor income $w L$ and through returns $r$ on its asset holdings $A$. The household's expenses include its consumption expenditures and the accumulation of assets $\dot{A}$ :

$$
\dot{A}=r A+w L-C \text {. }
$$

\section{$2.2 \quad$ Final Goods Sector}

The household's demand for the final goods is served by a representative producer. The production of the final goods requires $L_{Y}$ labor and $X$, which is a CES composite of the telecom goods $x_{j}, j=1, \ldots, N$, with an elasticity of substitution $\varepsilon$. Ceteris paribus the increasing demand for $X$ creates positive network externalities in the final goods production, which are measured by $\tilde{X}$. These externalities increase the productivity of the final goods producers. According to the literature (e.g., Leff, 1984), these externalities can increase the productivity of telecom goods users, for instance, through the increased capabilities for search and communication over distances.

The production of the final goods has a Cobb-Douglas technology and is given by

$$
\begin{aligned}
& Y=\tilde{X} X^{\sigma} L_{Y}^{1-\sigma}, \\
& X=\left(\sum_{j=1}^{N} x_{j}^{\frac{\varepsilon-1}{\varepsilon}}\right)^{\frac{\varepsilon}{\varepsilon-1}},
\end{aligned}
$$

where $1>\sigma>0$ and $\varepsilon>1$.

\subsection{The Telecommunications Industry}

At any time $t$ there are $N(t)$ producers in the telecommunications industry. At the same time, an entrepreneur (a potential producer) decides to enter. If it enters, it starts producing its distinct type of good.

Firm Entry: In order to enter and to generate its distinct type of good, the entrepreneur has to invest. It should borrow the resources for the investment from the household at interest rate $r$.

This investment generates, for instance, the physical capital/infrastructure of the entrant. It is in terms of the final goods and has its productivity $\eta>0$. The 
creation of the distinct type of good is given by

$$
\dot{N}=\eta S,
$$

where $\dot{N}$ is the new telecom good created by the investment $S$.

Telecom Goods Production: After its entry, the firm stays in the market forever. It discounts the future profit streams $\pi$ with the interest rate $r$.

For ease of exposition I take as an example some firm $j$. The production of telecom good $x_{j}$ requires $L_{x_{j}}$ labor input and has $\lambda_{j}$ productivity,

$$
x_{j}=\lambda_{j} L_{x_{j}}{ }^{7}
$$

In order to support a symmetric equilibrium, I assume that each and every telecom firm enters with the highest productivity available at the entry date.

The telecom firm can continuously improve its productivity by hiring labor $L_{r_{j}}$. The labor force employed in the productivity improvement/R\&D process uses firm's current knowledge about the production process in order to create a better one. Moreover, if the firm decides to license knowledge from other firms $\left(u_{i, j} \lambda_{i} ; \forall i \neq j, u_{i, j}\right.$ is the share of $\lambda_{i}$ that would go to the firm $j$ ), the labor force can use a set of composite knowledge for the same purpose. The composite knowledge is a CobbDouglas combination of the firm's knowledge with the ones of other firms. The only essential knowledge input in the $R \& D$ process is the one of the firm. The R\&D process has an exogenous efficiency level $\xi$ and is given by

$$
\dot{\lambda}_{j}=\xi\left[\sum_{i=1}^{N}\left(u_{i, j} \lambda_{i}\right)^{\alpha}\right] \lambda_{j}^{1-\alpha} L_{r_{j}}
$$

where $u_{j, j} \equiv 1, \xi>0$, and $1>\alpha>0$. This formulation of knowledge accumulation process ensures a balanced growth path. It also helps to isolate the effect of the market structure of the telecommunications industry on innovation and growth since $\mathrm{R} \& \mathrm{D}$ would be at its maximal level if there are no market imperfections (for more rigorous discussion of the properties of this knowledge production function and its implications, see Jerbashian, 2014).

The revenues of the firm are gathered from its supply of telecom good and knowledge $\left(u_{j, i} \lambda_{j} ; \forall j \neq i\right)$. The costs are the labor compensations and its demand for

\footnotetext{
${ }^{7}$ The model presented here can incorporate capital accumulation in telecom firms in addition to the (capital) investments of entrants. That could be modeled similarly to the entry rule (5) and could represent the infrastructure investments of incumbent firms. However, that would make the analytical results more cumbersome without changing the qualitative results of the model.
} 
knowledge. The firm maximizes the present discounted value of its profit streams. Formally,

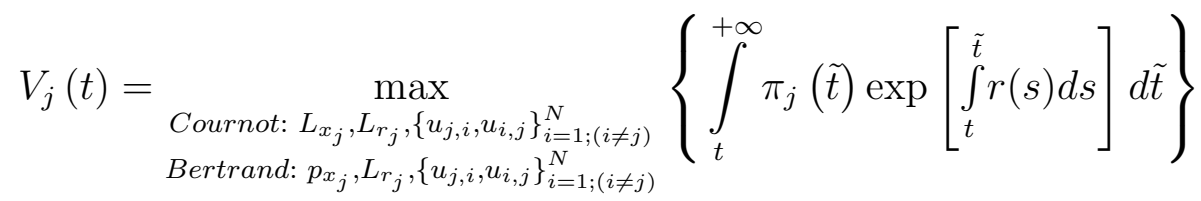

s.t.

$\pi_{j}=p_{x_{j}} x_{j}-w\left(L_{x_{j}}+L_{r_{j}}\right)+\left[\sum_{i=1, i \neq j}^{N} p_{u_{j, i} \lambda_{j}}\left(u_{j, i} \lambda_{j}\right)-\sum_{i=1, i \neq j}^{N} p_{u_{i, j} \lambda_{i}}\left(u_{i, j} \lambda_{i}\right)\right]$,

(6), (7),

where $t$ is the entry date, $p_{x_{j}}$ is the price of the telecom good $x_{j}, w$ is the wage rate, and $p_{u_{j, i} \lambda_{j}}$ and $p_{u_{i, j} \lambda_{i}}$ are the prices of $u_{j, i} \lambda_{j}$ and $u_{i, j} \lambda_{i}$. All the variables in the profit equation (9) are time dependant. Here and wherever it is relevant in the rest of the text, I have suppressed the time dependence of the variables for ease of exposition.

Given that telecom firms set prices in the output market, it seems natural to assume that as a licensor of knowledge these firms have a right to impose a take-it or leave-it offer. This assumption is maintained in the rest of the text. It implies that the price of knowledge is equal to the buyer's marginal valuation. ${ }^{8}$

\subsection{Equilibrium Conditions}

From the household's optimal problem follows the standard Euler equation:

$$
\frac{\dot{C}}{C}=\frac{1}{\theta}(r-\rho)
$$

This equation and the household's budget constraint (2) describe the paths of consumption and asset holdings.

In turn, normalizing the price of the final goods to 1 and using $P_{X}$ to denote the marginal product of $X$ in $Y$, from the final goods producer's problem it follows that

$$
\begin{aligned}
& w L_{Y}=(1-\sigma) Y, \\
& P_{X} X=\sigma Y,
\end{aligned}
$$

\footnotetext{
${ }^{8} \mathrm{I}$ assume that the licensors do not internalize the demand for knowledge.
} 


$$
\begin{aligned}
& x_{j}=X\left(\frac{P_{X}}{p_{x_{j}}}\right)^{\varepsilon}, \\
& P_{X} X=\sum_{j=1}^{N} p_{x_{j}} x_{j},
\end{aligned}
$$

where (11) is the final goods producer's labor demand. Equations (12)-(15) describe its demand for telecom goods.

I assume that in equilibrium the measure of externalities $\tilde{X}$ is given by

$$
\tilde{X}=X^{\mu}
$$

where $\mu$ measures the strength of these externalities and $1-\sigma>\mu \geq 0 .{ }^{9}$ These externalities generate gains with the use of telecommunications in two ways. First, higher use of telecommunications increases $X$ and $\tilde{X}$. In such a stylized framework, this can be thought to represent the traditional network externalities which stem from higher adoption and use of telecommunications. ${ }^{10}$ Second, ceteris paribus $X$ and $\tilde{X}$ increase with R\&D in the telecommunications industry. This can be thought to represent network externalities which stem from better (more productive) telecommunications for a given level of adoption and use. In this sense, network externalities $\tilde{X}$ stem from the effective adoption and use of telecommunications.

Meanwhile, using $q_{\lambda_{j}}$ and $e_{j}$ to denote the shadow value of productivity improvement and perceived elasticity of substitution, from the telecom firm $j$ 's problem it follows that

$$
\begin{aligned}
& w=\lambda_{j} p_{x_{j}}\left(1-\frac{1}{e_{j}}\right) \\
& w=q_{\lambda_{j}} \frac{\dot{\lambda}_{j}}{L_{r_{j}}} \\
& u_{j, i}=1, \forall i \neq j, \\
& p_{u_{i, j} \lambda_{i}}=q_{\lambda_{j}} \xi \alpha\left(\frac{\lambda_{j}}{u_{i, j} \lambda_{i}}\right)^{1-\alpha} L_{r_{j}}, \forall i \neq j \\
& \frac{\dot{q}_{\lambda_{j}}}{q_{\lambda_{j}}}=r-\left[(N-1) \frac{p_{u_{j, i} \lambda_{j}}}{q_{\lambda_{j}}}+\xi L_{r_{j}}\right. \\
& \left.\quad+\xi L_{r_{j}}(1-\alpha) \sum_{i=1, i \neq j}^{N}\left(\frac{u_{i, j} \lambda_{i}}{\lambda_{j}}\right)^{\alpha}+\left(1-\frac{1}{e_{j}}\right) \frac{p_{x_{j}}}{q_{\lambda_{j}}} L_{x_{j}}\right] .
\end{aligned}
$$

\footnotetext{
${ }^{9}$ It is necessary to have $1-\sigma>\mu$ in order for the production function of final goods (3) to be concave in $X$ in the Social Planner's problem.

${ }^{10}$ The way the network externalities are modeled here is equivalent to assuming that the value of using telecommunications increases with the volume of the use. If interpreted so, this way of modeling can be treated as a simplification for the sake of tractability.
} 
The first equation is the labor demand for telecom good production, or the supply of the telecom good. The second equation is the investment in R\&D (i.e., $w L_{r_{j}}$ ). The third and fourth equations are the supply of and demand for knowledge. The last equation is the internal rate of return on $R \& D$.

The perceived elasticity of substitution, $e_{j}$, depends on the type of competition. It can be shown that under Cournot $(C)$ competition it is given by

$$
e_{j}^{C}=\varepsilon\left\{1+\left[(\varepsilon-1) \frac{x_{j}^{\frac{\varepsilon-1}{\varepsilon}}}{\sum_{i=1}^{N} x_{i}^{\frac{\varepsilon-1}{\varepsilon}}}\right]\right\}^{-1}
$$

and under Bertrand $(B)$ competition it is given by

$$
e_{j}^{B}=\varepsilon-\left[\frac{(\varepsilon-1) p_{x_{j}}^{1-\varepsilon}}{\sum_{i=1}^{N} p_{x_{i}}^{1-\varepsilon}}\right] .
$$

In (22) and (23), the terms in square brackets measure the extent of strategic interactions among telecom firms. Moreover, these terms indicate the difference between the perceived elasticity of substitution, $e$, and the actual elasticity of substitution, $\varepsilon$. Therefore, they indicate some of the distortions in the economy which stem from imperfect competition. In a symmetric equilibrium, when the number of firms increases, these distortions tend to zero since the terms in square brackets tend to zero.

In equilibrium, final goods and labor markets clear:

$$
\begin{aligned}
& Y=C+S, \\
& L=L_{Y}+\sum_{j=1}^{N}\left(L_{x_{j}}+L_{r_{j}}\right) .
\end{aligned}
$$

Moreover, the amount of supplied knowledge is equal to the amount of demanded knowledge:

$$
\sum_{j=1}^{N} \sum_{i=1, i \neq j}^{N} p_{u_{j, i} \lambda_{j}}\left(u_{j, i} \lambda_{j}\right)=\sum_{j=1}^{N} \sum_{i=1, i \neq j}^{N} p_{u_{i, j} \lambda_{i}}\left(u_{i, j} \lambda_{i}\right)
$$

Under free entry into telecom, the entry investment (cost) is equal to the generated value from the entry for any telecom firm:

$$
V \dot{N}=S
$$


This means that the telecom firms compensate the households for the borrowed capital from their operating profits/generated value. ${ }^{11}$

Together with the entry rule (5) this condition implies that in free entry equilibrium the incumbents' value is given by

$$
V=\frac{1}{\eta}
$$

\section{Features of the Dynamic Equilibrium}

I restrict the attention to a symmetric equilibrium in the telecommunications industry and balanced growth path analysis. It is instructive to derive the profit function of a telecom firm first. In order to do so, I use $g_{Z}$ to denote the growth rate of a variable $Z$ and denote

$$
\begin{aligned}
& \Phi(N)=\frac{1}{e^{k}-1}-\frac{g_{\lambda}}{r-\left(g_{w}-\delta g_{N}\right)}, k=C, B, \\
& \delta=1(\dot{N} \neq 0) .
\end{aligned}
$$

After a tedious algebra one can write the profit function of a telecom firm as $\pi=$ $w L_{x} \Phi(N)$.

Proposition $1 \Phi(N)$ is a decreasing and convex function.

Proof. See Online Appendix A.1.

The competition intensifies with the number of firms $N$. When strategic interactions in the product market are non-negligible, the intensity of competition and profits are related negatively. The result that $\Phi(N)$ is a decreasing function reflects exactly this point.

\subsection{Balanced Growth}

I denote the growth rate of the final output by $g$.

Proposition 2 The constant growth rate of final output is given by

$$
g=\psi g_{\lambda}
$$

\footnotetext{
${ }^{11}$ Therefore, the households are entitled to the cash flows of telecom firms and, at the level of the abstraction in this model, they can be thought to be venture capitalists.
} 
where

$$
\begin{aligned}
& \psi=\frac{(\mu+\sigma)(\varepsilon-1)}{\varepsilon-1-\delta(\mu+\sigma)}, \\
& g_{\lambda}=\frac{\xi D L-\rho}{(\theta-1+\delta) \psi+D}, \\
& D=\frac{b \sigma}{b \sigma+1-\sigma}, \\
& b=\frac{e^{k}-1}{e^{k}}, k=C, B .
\end{aligned}
$$

Proof. See Online Appendix A.1.

Proposition 3 The labor force allocations on the balanced growth path are given by

$$
\begin{aligned}
& N L_{r}=\frac{1}{\xi} g_{\lambda}, \\
& N L_{x}=\frac{1}{\xi}\left[(\theta-1+\delta) \psi g_{\lambda}+\rho\right], \\
& L_{Y}=L-N\left(L_{x}+L_{r}\right),
\end{aligned}
$$

where $N L_{r}, N L_{x}$, and $L_{Y}$ are the shares of labor force employed in the $R \mathscr{E} D$ process, the production of telecom goods, and in the production of final goods, respectively.

Proof. See Online Appendix A.1.

The expression in (31) provides some of the key insights. In (31), $g_{\lambda}$ is the rate of growth in the telecommunications industry, and $\psi$ captures the contribution of growth in this industry to the growth of final output. In turn, $\psi g_{\lambda}$ represents the contribution of the telecommunications industry to the growth of final output since the model abstracts from other potential sources of growth.

The contribution of growth in the telecommunications industry to the growth of final output, $\psi$, depends on, for example, the magnitude of network externalities, $\mu$. In turn, innovative effort (36) and growth (33) in the telecommunications industry depend on the strength of competitive pressures in the telecommunications industry, which are captured in $D$. Competitive pressures appear to matter for innovation because they affect the prices of telecom goods. The changes in the prices of telecom goods affect the demand for these goods and the labor force allocations (36)-(38).

The main comparative statics are offered below. I analyze two cases in order to highlight the effect of regulations, market structure, and entry. In the first case, I assume that there are exogenous barriers to entry into the telecommunications industry (i.e., the number of telecom firms is exogenously fixed). I call this case 
"Barriers to Entry." It can be thought to represent a situation when policy makers regulate entry into the telecommunications industry and the number of telecom firms. The second case I call "Endogenous Entry" and assume no exogenous barriers. This case resembles a situation when entry into the telecommunications industry is not regulated.

\subsubsection{Barriers to Entry}

With a fixed number of telecom firms the economy grows at constant rates. When there are (exogenous) barriers to entry $\delta$ is equal to 0 .

Corollary 4 The growth rate of final output, $g$, is positively related to the number of telecom firms, toughness of competition (Bertrand vs Cournot) and to the strength of network externalities, $\mu$.

The growth rate of final output increases with the number of telecom firms since higher number of firms implies more intensive competition. This reduces the relative price distortions that are a result of price setting by telecom firms [i.e., $1 / e$ in (17) decreases]. Since the final goods producers use labor for production, the relative price distortions matter for growth through labor allocations. ${ }^{12}$ Lower distortions imply higher growth because they are associated with higher R\&D effort and growth in the telecommunications industry (i.e., $N L_{r}$ and $g_{\lambda}$ increase with lower distortions). This is also the driver behind the positive relation between the toughness of competition and the growth rate of final output. Such a positive relation holds because $e^{B} \geq e^{C}$ for any given $N$ and $\varepsilon$. The difference between the perceived elasticities of substitution $e^{C}$ and $e^{B}$ is large for relatively low values of $N$. Therefore, $g_{\lambda}$ and $g$ increase more with the toughness of competition when the number of firms is low. The difference between $e^{C}$ and $e^{B}$ dissipates, however, as $N$ grows to infinity. ${ }^{13}$ These results imply that policies, which motivate entry into the telecommunications industry and toughen competition, can promote innovation and growth.

The growth rate of final output increases with the strength of network externalities $\mu$ since $\psi$ increases with $\mu$. It follows from (33), however, that innovation and growth in the telecommunications industry decline with $\mu$. This is because, higher $\mu$ does not affect the balance between the demand for the bundle of telecom goods $X$ and $L_{Y}$ and in this sense does not alter the production and R\&D incentives of

\footnotetext{
${ }^{12}$ In an extreme case when the final goods producers do not use labor, the $b$ in (35) and the $\sigma$ are equal to one and the relative price distortions do not matter for growth.

${ }^{13}$ For example, if $\varepsilon=2.5$ and $N=2$ then $e^{C}=1.43$ and $e^{B}=1.75$. In this example, the difference between $e^{C}$ and $e^{B}$ is significant at least relative to the value of $\varepsilon$.
} 
telecom firms. Meanwhile, in equilibrium it increases $g$ and interest rate $r$ [see (10)], which discourages investments in R\&D and reduces $N L_{r}$ and $g_{\lambda}$.

Before proceeding further with the comparative statics analysis, it is useful to consider the function $\Phi$ one more time. On balanced growth path it is given by

$$
\Phi(N)=\frac{1}{e^{k}-1}-\frac{g_{\lambda}}{(\theta-1+\delta) \psi g_{\lambda}+\rho}, k=C, B
$$

The profit of a telecom firm will be non-negative if and only if $\Phi(N)$ is non-negative. In terms of $g_{\lambda}, \Phi(N) \geq 0$ is equivalent to

$$
g_{\lambda} \leq \frac{\rho}{e^{k}-1-(\theta-1+\delta) \psi}, k=C, B .
$$

Hereafter, I call the growth rate in the telecommunications industry, $g_{\lambda}$, which satisfies the equality in (40) $Z P$, i.e., zero profit. In turn, I call $C M E$ the growth rate of $\lambda$ which was derived from the capital market equilibrium [i.e., (33)]. Given $N$ if $C M E$ is lower (higher) than $Z P$ the profits of the telecom firms are positive (negative).

It is straightforward to show that $Z P$ is a convex and decreasing function of the number of telecom firms, $N$, as long as the denominator of (40) is positive, whereas $C M E$ is a concave and increasing function of $N$. ZP declines with $N$ since the higher $N$ implies lower profits and lower amount of recourses that can be devoted to R\&D.

Depending on the household's preferences, final goods production technology, and R\&D technology of telecom firms there are two cases in the economy. In the first case, $C M E$ is lower than $Z P$ for any $N$. While in the second case, there is some $N^{*}$ number of firms such that when $N>N^{*}, C M E$ is higher than $Z P$. In the first case there can be infinitely many telecom firms in the economy since the profits, thus the value $V$, are always positive. In other words, the number of telecom firms can become arbitrarily large if regulations permit that. In contrast, in the second case the maximum number of telecom firms has a finite upper bound. Therefore, the number of telecom firms cannot become arbitrarily large even if regulations permit that (unless there are subsidies to entry).

An important determinant of these cases is the market power of the telecom firms. Ceteris paribus, the second case would hold under lower market power. For instance, under Cournot type of competition the first case holds for the following values of model parameters $\varepsilon=2, \sigma=0.05, \mu=0.005, \theta=5, \rho=0.02, \xi=1$, and 
$L=1$. The second case holds when $\varepsilon=3$ and everything else is held the same. ${ }^{14}$

Proposition 5 The upper bound in the second case can be derived from a zero profit condition, which is equivalent to a zero value condition.

Proof. 1. The equivalence follows from the fact that $V$ is the sum of discounted profits.

2. $\Phi(N)$ is continuous and decreasing in $N$. Therefore, the maximum number of firms is given by a zero profit condition.

It is important to highlight the continuity of $\Phi(N)$ since, according to entry rule (5) and market clearing condition for entry investments (27), the firm $N^{*}$ for which $Z P$ and $C M E$ intersect is not in the telecom market. Therefore, $N^{*}$ can be treated as an upper bound for the number of firms in the market.

These two cases are illustrated in $\left(g_{\lambda}, N\right)$ space in Figure 1, where the maximum number of telecom firms is denoted by $N^{*}$ if it exists. This figure suggests that there are regions of $N$ where the fixed number of telecom firms can be set higher while holding the profits non-negative. If the fixed number of telecom firms is in those regions, then policies which increase the number of telecom firms, imply higher growth in productivity of telecom firms, since the latter moves along $C M E$. Clearly, such policies also imply higher economic growth [see (31)].

\subsubsection{Endogenous Entry}

In case there are no exogenous barriers to entry $C M E$ and $Z P$ are useful for characterizing the features of the equilibrium.

Proposition 6 Since CME increases with the number of firms and ZP declines with it, the equilibrium is always stable.

Proof. See Online Appendix A.2 for stability conditions.

Moreover, depending on the household's preferences, final goods production technology and the R\&D technology of telecom firms, there are two cases when the economy grows at constant rates. In the first case there are so many telecom firms that the new entrant's impact on others' demand is negligible. Whereas in the second case, the next entrant will have negative profit streams (i.e., there are endogenous barriers to entry). ${ }^{15}$

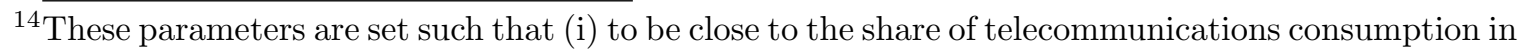
the US; (ii) to be close to the suggestion of Röller and Waverman (2001) on the average contribution of telecommunications to economic growth in the US; and (iii) to have low elasticity of substitution between telecom goods.

${ }^{15}$ This ordering is possible because $\Phi(N)$ decreases with $N$ and investments in R\&D are fixed costs.
} 

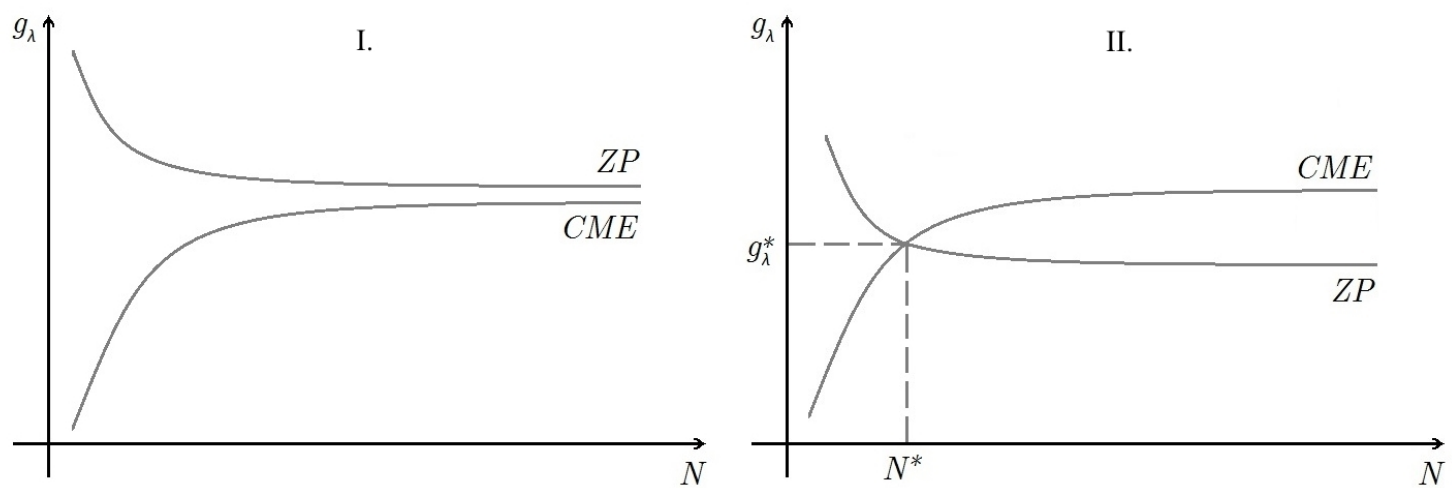

Note: This figure illustrates $C M E\left[g_{\lambda}\right.$ from (33)] and $Z P\left[g_{\lambda}\right.$ from (40)] as functions of the number of telecom firms, $N$. Part I of this figure corresponds to the case when $C M E$ and $Z P$ do not intersect for any finite $N$. It is obtained for Cournot type of competition and the following values of model parameters: $\varepsilon=2, \sigma=0.05, \mu=0.005$, $\theta=5, \rho=0.02, L=1$, and $\xi=1$. Part II corresponds to the case when $C M E$ and $Z P$ intersect at a finite number of telecom firms, $N^{*}$. It is obtained for Cournot type of competition and the following values of model parameters: $\varepsilon=3, \sigma=0.05, \mu=0.005, \theta=5, \rho=0.02, L=1$, and $\xi=1$.

In the first case, $C M E$ is always lower than $Z P$. On the balanced growth path there are infinitely many telecom firms and there is permanent entry. The growth rate of final output in this case is given by (31), where $\delta$ is equal to 1 . Therefore, it depends on the same factors as in the case of exogenous barriers. However, neither the number of telecom firms nor the type of competition affect it. This holds because the strategic interactions are negligible and the perceived elasticities of substitution are equal to $\varepsilon$.

Corollary 7 When there are exogenous barriers to entry and infinitely many telecom firms, then the growth rate of final output is higher than the growth rate of final output when there is entry.

There are two forces behind this result. First, the contribution of growth in the telecommunications industry to the growth of final output, $\psi$, is lower when there are exogenous barriers to entry and infinitely many telecom firms than when there is entry [see $\delta$ in the denominator of (32)]. Therefore, for a given $g_{\lambda}$ the growth rate of final output is higher when there is entry. This implies that interest rate, $r$, is also higher when there is entry. Higher interest rate reduces the incentives to conduct $\mathrm{R} \& \mathrm{D}$ and $g_{\lambda}$ declines. This effect is captured by higher $\psi$ in the denominator of (33). Second, returns on R\&D decline with the entry of telecom firms since the entry decreases the demand for a telecom good. When the returns decline, telecom firms cut their investments in R\&D and $g_{\lambda}$ declines. This effect is captured by $\delta=1$ in the denominator of (33). This result holds then because these two forces reduce 
$g_{\lambda}$ more than $\psi$ increases.

In the second case of Endogenous Entry, let $N^{* *}(<+\infty)$ be the last telecom firm that will have non-negative profit streams if it enters.

Proposition 8 There is no entry after $N^{* *}$ and $N^{* *}$ is determined from the intersection of $C M E$ and $Z P$ [point $\left(g_{\lambda}^{*}, N^{*}\right)$ in part II of Figure 1].

Proof. There is no entry after $N^{* *}$ since for any $N>N^{* *}$ the value $V$ would be negative. ${ }^{16}$ When there is no entry, the economy is on a balanced growth path. Therefore, $N^{* *}$ is determined from the intersection of $C M E$ and $Z P$.

Corollary 9 Under Cournot and Bertrand competitions, the number of firms are given by

$$
N^{C}=\frac{(\varepsilon-1) \xi \sigma L[(\theta-1)(\sigma+\mu)+1]}{\varepsilon(\xi \sigma L-\rho)-\xi \sigma L[(\theta-1)(\sigma+\mu)+1]},
$$

and

$$
N^{B}=\frac{(\varepsilon-1)(\xi \sigma L-\rho)}{\varepsilon(\xi \sigma L-\rho)-\xi \sigma L[(\theta-1)(\sigma+\mu)+1]},
$$

respectively.

Proof. See Online Appendix A.3.

Corollary 10 The growth rate of final output is the same under both types of competition. However, under Bertrand competition the number of telecom firms is less than under Cournot competition.

This result implies that policies, which toughen competition, might reduce balanced growth path welfare if consumers have love for variety. As previously, it can be also shown that the growth rate of the final output increases with $\mu$.

\subsection{Social Optimum}

In this section I compare the decentralized equilibrium allocations and growth rates with those of the Social Planner's solution and analyze the sources of any difference. The Social Planner selects a feasible path that maximizes the lifetime utility of the household. In the social optimum, symmetry holds in the telecommunications industry due to symmetry in knowledge for production of telecom goods. Moreover,

\footnotetext{
${ }^{16}$ Strictly speaking, the firm that has zero profits invests zero. Therefore, according to (5), it also does not enter. This implies that $N^{* *}$ is the upper bound for the number of firms in the telecom market. However, since $\Phi$ is a continuous function of the number of firms, $N^{* *}$ is exactly the number of firms in the market.
} 
there is no market for that knowledge, instead, it is shared across the telecom goods producers. As in decentralized equilibrium, I focus on the balanced growth path inference. Online Appendix B.1 presents the Social Planner's problem.

Proposition 11 The socially optimal growth rate of final output is given by

$$
g^{S}=\psi^{S} g_{\lambda}^{S}
$$

where

$$
\begin{aligned}
\psi^{S} & =\frac{(\varepsilon-1)(\sigma+\mu)}{\varepsilon-1-(\sigma+\mu)}, \\
g_{\lambda}^{S} & =\frac{\xi D^{S} L-\rho}{(\theta-1) \psi^{S}+D^{S}}, \\
D^{S} & =\frac{\sigma+\mu}{1+\mu} .
\end{aligned}
$$

In turn, the socially optimal labor allocations are given by

$$
\begin{aligned}
& N L_{r}^{S}=\frac{1}{\xi} g_{\lambda}^{S}, \\
& N L_{x}^{S}=D^{S}\left(L-N L_{r}^{S}\right), \\
& L_{Y}^{S}=L-N L_{x}^{S}-N L_{r}^{S} .
\end{aligned}
$$

Proof. See Online Appendix B.1.

In (43), $\psi^{S}$ is the analogue of $\psi$. It measures the contribution of growth in the telecommunication industry to the growth of final output in the social optimum. In turn, $\psi^{S} g_{\lambda}^{S}$ measures the contribution of telecommunications industry to the growth of final output in the social optimum.

Corollary 12 There is permanent entry in the social optimum.

The permanent entry result is due to the absence of market incentives in the social optimum. It stands in contrast to the decentralized equilibrium result where it may be the case that there are endogenous barriers to entry. It holds because R\&D in the telecommunications industry increases the marginal product of $N$. From the Social Planner's problem it can be also shown that the analogue of the profit function in the social optimum is constant and greater than zero. If such a relation would hold in a decentralized equilibrium, then there would also be permanent entry.

It can be also shown that the socially optimal growth rate of the final output increases with the strength of network externalities $(\mu)$. As in the decentralized 
equilibrium, this holds because higher $\mu$ implies higher contribution of growth in the telecommunications industry and entry into this industry to growth.

Corollary 13 In the social optimum the share of labor force allocated to R\&D is higher than that in the decentralized equilibrium (i.e., $N L_{r}^{S}>N L_{r}$ ).

Proof. See Online Appendix B.2 and Online Appendix B.3.

It can be easily shown that this result follows from two factors. First, the telecom firms are price setters, which creates relative price distortions. These distortions reduce the incentives to invest in $R \& D$ since they increase the price of $R \& D$ inputs of these firms. The comparison of $D$ and $D^{S}$ from (34) and (46) reveals this factor. Second, in the decentralized equilibrium the rate of return on $R \& D$ declines with the entry of telecom firms. Thus, when there is permanent entry telecom firms cut their R\&D investments [see $\delta$ in the denominator of (33)]. In contrast, the Social Planner has no market incentives. Therefore, it does not have any incentive to cut investments in R\&D in the telecommunications industry.

At the first glance, the comparison of $D$ and $D^{S}$ can suggest that the network externalities may be a third factor. The presence of these externalities also creates resource misallocation through relative price distortions, which are due to the not internalized value from using telecom goods. However, the effect of these externalities, as measured by their strength $\mu$, on $N L_{r}$ relative to the same effect on $N L_{r}^{S}$ is ambiguous, and the proposition $N L_{r}^{S}>N L_{r}$ holds for any $\mu$.

Given that in the social optimum the share of labor force employed in R\&D in the telecommunications industry is greater than that in the decentralized equilibrium, the growth rate in this industry in the social optimum is higher than that in the decentralized equilibrium, $g_{\lambda}^{S}>g_{\lambda}$. Since in the social optimum there is permanent entry, and in the decentralized equilibrium there can be endogenous barriers to entry, $\psi^{S}$ from (44) is greater than or equal to the $\psi$ from (32). Therefore, the growth rate of final output is also higher in the social optimum, $g^{S}>g$. These results suggest that there is a scope of growth and welfare enhancing policies.

\subsection{Policy Inference}

In this section, I consider a government which sets policies that deliver the socially optimal allocations as a decentralized equilibrium outcome in the long-run. The policy instruments available to the government are taxes and subsidies, and market structure regulation in the telecommunications industry. In view of the results above, I suggest these "optimal" policies. 
In search of optimal policies the sources of the differences between the socially optimal and decentralized equilibrium outcomes should be taken into account. In order to highlight the direction of an optimal policy, the following list briefly summarizes these sources. In the decentralized equilibrium

- due to the price setting behavior of the telecom firms, there are relative price distortions;

- the telecom firms under-invest in R\&D. Moreover, ceteris paribus, they under-invest more when there is entry of telecom firms since their returns decline with the entry;

- the network externalities are not internalized, which also creates relative price distortions; and

- there can be endogenous barriers to entry, in contrast to the social optimum where there is permanent entry.

In order to eliminate these differences, the optimal policy would fix the resource misallocations through corrections in relative prices. As a market structure regulation, it would allow free entry into the telecommunications industry and would subsidize the entry, if needed.

A policy, under which the decentralized equilibrium allocations are the same as the socially optimal ones, subsidizes the demand for telecom goods $\left(\tau_{x}\right)$. Further, it transfers to telecom firms subsidies proportional to the value of knowledge $\left(\tau_{\lambda}\right)$. It also makes lump-sum transfers to telecom firms $\left(T_{\pi}\right)$ and finances these subsidies and transfers through a lump-sum tax imposed on the household $(T)$. Online Appendix $\mathrm{C}$ derives this policy. Formally, it is given by

$$
\begin{aligned}
& \tau_{x}=1-b \frac{\sigma}{\sigma+\mu}, \\
& \tau_{\lambda}=\frac{N}{\alpha} \psi^{S}, \\
& T_{\pi}: \pi \equiv \nu=\frac{\theta}{\eta}\left(g^{S}+\rho\right), \\
& T=N\left(\tau_{x} p_{x} x+\tau_{\lambda} p_{\lambda} \lambda+T_{\pi}\right) .
\end{aligned}
$$

The subsidy rate $\tau_{x}$ corrects the demand for telecom goods. It takes into account the price distortions that stem from market power of telecom firms and network externalities. The subsidy to a telecom firm proportional to the value of knowledge $\tau_{\lambda}$ eliminates the effect of entry into the telecommunications industry on the rate of 
return on $\mathrm{R} \& \mathrm{D}$. In other words, $\tau_{\lambda}$ eliminates the $\delta$ in the denominator of (33) given that there is entry of firms. In turn, $T_{\pi}$ is a lump-sum transfer that keeps the profit of the telecom firm constant and non-negative in order to guarantee permanent entry. Formally, $\nu$ is equal to $r^{S} V$, where $r^{S}$ is the return on assets in the social optimum. ${ }^{17}$ This transfer is negative if, for example, the elasticity of substitution $\varepsilon$ is relatively small number and $\psi^{S}$ is relatively large (i.e., $\psi^{S} \approx 1$ ). It is positive if $\psi^{S}$ is small and the elasticity of substitution between telecom goods is high.

Given that this model focuses on market economy, its policy recommendations do not take into account (usually limited) public ownership of telecom firms as can be observed at least in a handful of countries. Therefore, they might overemphasize the need for subsidies if the objective of the public owners is to use their control for maximizing social surplus. ${ }^{18}$ Nevertheless, many recently implemented policies seem to have a structure which is similar to the one of the suggested optimal policies. The similarities are that those policies promote demand for telecom goods and as a regulation they motivate entry (Table 1 in Online Appendix D illustrates how the market structure of the telecommunications industry has changed in recent decades in several major economies). A prominent example of such a policy is the Telecommunications Act of 1996. Despite these similarities, the implemented policies tend to lack important components. They overlook the incentive of telecom firms to under-invest in $R \& D$ and the negative effect of entry on the rate of return on that investment. ${ }^{19}$ They also do not incorporate transfers which could allow permanent entry, if needed.

\section{Conclusions}

This paper presents a model where the telecommunications industry is the engine of growth. In such a framework, it focuses on balanced growth path and symmetric equilibrium analysis. It shows that the contribution of the telecommunications industry to long-run growth increases with the strength of (direct) network externalities. Moreover, it shows that increasing the number of telecom firms and/or the toughness of competition motivates R\&D investments in the telecommunications industry and increases its contribution.

Modeling entry into the telecommunications industry, it also shows that depend-

${ }^{17}$ The expression $r^{S} V$ is the analogue of the profit function of a telecom firm in the social optimum. ${ }^{18}$ Alternatively, further policy measures would be required if public owners exacerbate the distortions.

${ }^{19}$ The Federal Communications Commission (FCC) in the US envisions the need to foster innovation in the telecommunications industry (see, for instance, the strategic plan of FCC for 2008). However, the FCC tries to foster innovation by the means of entry and more competition in the telecommunications industry. 
ing on the economy, in the long-run, there can be endogenous barriers to entry or entry continues forever. In both cases the growth rate of the final output does not depend on the toughness of competition and the number of telecom firms.

These decentralized equilibrium outcomes are far from the social optimum according to the model. There are three reasons to observe such a divergence. First, there are relative price distortions, thus resource misallocations, in the decentralized equilibrium due to the imperfect competition in the telecom market and because the competitive forces do not internalize the network externalities. Second, in the decentralized equilibrium the rate of return on $R \& D$ declines with the entry of telecom firms, which is not the case in the social optimum. Third, there is permanent entry in the social optimum, which may not be the case in the decentralized equilibrium. The last two take place because the market incentives are neglected in the social optimum. These three aspects imply that the long-run growth rate in social optimum is higher than the decentralized equilibrium one and that telecom firms under-invest in $R \& D$ in the decentralized equilibrium.

Given these observations, the policies which can increase growth and welfare in the decentralized equilibrium in the long-run (i) subsidize the demand for telecom goods; (ii) motivate $\mathrm{R} \& \mathrm{D}$ in the telecommunications industry through subsidies; and (iii) allow entry and, if needed, subsidize it.

The employed model is well suited for the purpose of this paper because it allows accounting for the channels through which the telecommunications industry and its market structure can affect long-run growth. This model, however, abstracts from many of the complex details of the telecommunications industry such as, for example, platform and platform-service level interactions and state ownership. Admittedly, this limits the sharpness of its inference for the telecommunications industry and policy recommendations. An interesting avenue of further research incorporates these details to deliver a sharper inference. 


\section{References}

Aghion, P., N. Bloom, R. Blundell, R. Griffith, and P. Howitt (2005). Competition and innovation: An inverted-U relationship. Quarterly Journal of Economics 120(2), 701-728.

Barone, G. and F. Cingano (2011). Service regulation and growth: Evidence from OECD countries. Economic Journal 121(555), 931-957.

Belderbos, R., M. Carree, , and B. Lokshin (2004). Cooperative R\&D and firm performance. Research Policy 33, 1477-1492.

Blundell, R., R. Griffith, and J. M. van Reenen (1999). Market share, market value and innovation in a panel of British manufacturing firms. Review of Economic Studies 66(3), 529-554.

Bourreau, M. and P. Doğan (2001). Regulation and innovation in the telecommunications industry. Telecommunications Policy 25(3), 167-184.

Boylaud, O. and G. Nicoletti (2001). Regulation, market structure and performance in telecommunications. OECD Economic Studies No. 32.

Czernich, N., O. Falck, T. Kretschmer, and L. Woessmann (2011). Broadband infrastructure and economic growth. Economic Journal 121(552), 505-532.

Gandal, N. (1995). Competing compatibility standards and network externalities in the PC software market. Review of Economics and Statistics 7r(4), 599-608.

Griffith, R., R. Harrison, and H. Simpson (2010). Product market reform and innovation in the EU. Scandinavian Journal of Economics 112(2), 389-415.

Grindley, P. C. and D. J. Teece (1997). Managing intellectual capital: Licensing and cross-licensing in semiconductors and electronics. California Management Review 39(2), 8-41.

Hagedoorn, J. (1993). Understanding the rationale of strategic technology partnering: Interorganizational modes of cooperation and sectoral differences. Strategic Management Journal 14(5), 371-385.

Hagedoorn, J. (2002). Inter-firm R\&D partnerships: An overview of major trends and patterns since 1960. Research policy 31(4), 477-492.

Hashmi, A. R. (2013). Competition and innovation: The inverted-U relationship revisited. Review of Economics and Statistics 95(5), 1653-1668.

Jerbashian, V. (2014). Knowledge licensing in a model of R\&D-driven endogenous growth. UB Economics Working Papers, wp. 2014/304.

Koutroumpis, P. (2009). The economic impact of broadband on growth: A simultaneous approach. Telecommunications Policy 33(9), 471-485.

Leff, N. H. (1984). Externalities, information costs, and social benefit-cost analy- 
sis for economic development: An example from telecommunications. Economic Development and Cultural Change 32(2), 255-276.

$\mathrm{Li}, \mathrm{W}$. and L. Xu (2004). The impact of privatization and competition in the telecommunications sector around the world. Journal of Law and Economics 47(2), 395430 .

Minniti, A. (2010). Product market competition, r\&d composition and growth. Economic Modelling 27(1), 417-421.

Oulton, N. (2012). Long term implications of the ICT revolution: Applying the lessons of growth theory and growth accounting. Economic Modelling 29(5), $1722-1736$.

Paleologos, J. M. and M. L. Polemis (2013). What drives investment in the telecommunications sector? Some lessons from the OECD countries. Economic Modelling 31, 49-57.

Röller, L.-H. and L. Waverman (2001). Telecommunications infrastructure and economic development: A simultaneous approach. American Economic Review 91 (4), 909-923.

Romer, P. M. (1990). Endogenous technological change. Journal of Political Economy $98(5), 71-102$.

Smulders, S. and T. van de Klundert (1995). Imperfect competition, concentration and growth with firm-specific R\&D. European Economic Review 39(1), 139-160.

Stiroh, K. J. (2003). Are ICT spillovers driving the New Economy? Review of Income and Wealth 48(1), 33-57.

van de Klundert, T. and S. Smulders (1997). Growth, competition and welfare. Scandinavian Journal of Economics 99(1), 99-118.

Venturini, F. (2007). ICT and productivity resurgence: A growth model for the information age. The B.E. Journal of Macroeconomics (Contributions) 7(1).

Vives, X. (2008). Innovation and competitive pressure. Journal of Industrial Economics 56(3), 419-469.

Vourvachaki, E. (2009). Information and communication technologies in a multisector endogenous growth model. CERGE-EI Working Papers, wp. 386.

\section{Acknowledgements}

I am grateful to Johannes M. Bauer, Marc Bourreau, Levent Çelik, Byeongju Jeong, Štěpán Jurajda, Peter Katuščák, Michal Kejak, Sergey Slobodyan, Evangelia Vourvachaki, Krešimir Žigić, the Editor and four anonymous referees for valuable comments. Earlier drafts of this paper have benefitted from the comments from conference participants at the 23rd ITS European Conference in Vienna (2012), Conference 
ICT in Paris (2012), 10th International IO Conference in Arlington, VA (2012), Management and Economics of ICT Conference in Munich (2012), 1st Armenian Economic Association meeting in Yerevan (2011), DEGIT in Saint Petersburg (2011), International Conference "Challenges of Europe" in Split (2011), 6th Biennial CES Conference in Prague (2010), and Bratislava Economic Meeting 2010. The financial support of GA UK grant No 79310, the Spanish Ministry of Education and Science grant ECO2012-34046, and the Generalitat of Catalonia grant 2014SGR493 is gratefully acknowledged. I also thank the LMU Management Alumni for the honor of the scholarship "Excellent Contributions from Ph.D. Students" at Management and Economics of ICT Conference in Munich in 2012 and the Czech Economic Society for the honor of the "Young Economist Award (2nd place)" in 2011. All errors remaining in this text are the responsibility of the author. 


\section{Online Appendices (not intended for publication)}

\subsection{Online Appendix A.1}

The optimal rules (17)-(21) follow from the telecom firm $j$ 's problem. In terms of current value Hamiltonian, firm $j$ 's problem is given by

$$
\begin{aligned}
H_{j}^{T} & =\max _{\left\{L_{x_{j}}, L_{r_{j}}, u_{j, i}, u_{i, j}\right\}}\left\{p_{x_{j}} \lambda_{j} L_{x_{j}}-w\left(L_{x_{j}}+L_{r_{j}}\right)\right. \\
& \left.+\left[\sum_{i=1, i \neq j}^{N} p_{u_{j, i} \lambda_{j}}\left(u_{j, i} \lambda_{j}\right)-\sum_{i=1, i \neq j}^{N} p_{u_{i, j} \lambda_{i}}\left(u_{i, j} \lambda_{i}\right)\right]+q_{\lambda_{j}} \xi\left[\sum_{i=1}^{N}\left(u_{i, j} \lambda_{i}\right)^{\alpha}\right] \lambda_{j}^{1-\alpha} L_{r_{j}}\right\} .
\end{aligned}
$$

Clearly, it is optimal to sell all the knowledge since it strictly increases the profits, i.e., $u_{j, i}=1$ for any $i$.

The ratio $1 / e_{j}$ in (17) and (21) stems from taking the derivative of the price of telecom good $j$ with respect $L_{x_{j}}$ and $\lambda_{j}$, correspondingly. In turn, from (17) and (18) it follows that

$$
\frac{p_{x_{j}}}{q_{\lambda_{j}}}=\frac{g_{\lambda_{j}}}{L_{r_{j}} b_{j}}
$$

where $b_{j}=\left(e_{j}-1\right) / e_{j}$.

Assuming symmetric equilibrium, the following can be obtained from (7), (54), and (21):

$$
g_{q_{\lambda}}=r-\left(g_{\lambda}+\frac{L_{x}}{L_{r}} g_{\lambda}\right)
$$

From (18) and(55) it follows that

$$
g_{q_{\lambda}}=g_{w}-\delta g_{N}-g_{\lambda},
$$

and

$$
N L_{r}=\frac{g_{\lambda}}{r-\left(g_{w}-\delta g_{N}\right)} N L_{x}
$$

From (17)-(21) and the market clearing condition (26), it follows that $\pi=w L_{x} \Phi(N)$, where

$$
\Phi(N)=\frac{1}{e^{k}-1}-\frac{g_{\lambda}}{r-\left(g_{w}-\delta g_{N}\right)}, k=C, B{ }^{20}
$$

\footnotetext{
${ }^{20}$ One way of deriving the profit function is by (i) inserting the demand for any other's knowledge (20) into the rate of return on $\mathrm{R} \& \mathrm{D}$ (21); (ii) using the market clearing condition (26) and the supply of knowledge (19) in the resulting equation in order to eliminate $p_{u_{j, i} \lambda_{j}}$ and $u_{j, i} \lambda_{j}$; (iii) using the investment in R\&D (18) in order to express the rate of return on R\&D; (iv) using the supply of the telecom good (17) and the investment in R\&D (18) in order to find the ratio of labor
} 
To show that $\Phi(N)$ is decreasing and convex function, first, I consider its first term. It can be shown that

$$
\frac{\partial e^{k}}{\partial N}>0, \frac{\partial^{2} e^{k}}{\partial N^{2}}<0, k=C, B .
$$

This means that the first term is decreasing and convex function of $N$. For the second term,

$$
\frac{\partial}{\partial N} \frac{g_{\lambda}}{r-\left(g_{w}-\delta g_{N}\right)}=\frac{\frac{N L_{x}}{L_{Y}}\left(\frac{\partial}{\partial N} \frac{N L_{r}}{L_{Y}}\right)-\frac{N L_{r}}{L_{Y}}\left(\frac{\partial}{\partial N} \frac{N L_{x}}{L_{Y}}\right)}{\left(\frac{N L_{x}}{L_{Y}}\right)^{2}}
$$

where

$$
\begin{aligned}
\frac{\partial}{\partial N} \frac{N L_{x}}{L_{Y}} & =\frac{\partial b}{\partial N} \frac{1}{b} \frac{N L_{x}}{L_{Y}} \\
\frac{\partial}{\partial N} \frac{N L_{r}}{L_{Y}} & =\frac{\partial b}{\partial N} \frac{1}{b}\left(\frac{N L_{r}+L_{Y}}{L_{Y}}\right) .
\end{aligned}
$$

Therefore,

$$
\frac{\partial}{\partial N} \frac{g_{\lambda}}{r-\left(g_{w}-\delta g_{N}\right)}=\frac{\partial b}{\partial N} \frac{1-\sigma}{b^{2} \sigma} .
$$

It can be shown that

$$
\frac{\partial b}{\partial N}>0, \frac{\partial b}{\partial N^{2}}<0 .
$$

Therefore, the second term is also decreasing and convex function of the number of firms. Hence, the $\Phi(N)$ is a decreasing and convex function.

\section{Balanced Growth}

Under symmetry and on a balanced growth path, all variables in (56) are time invariant. The return on asset holdings, $r$, is time invariant due to the standard Euler equation. The growth rates are time invariant by definition. The total labor force employed in the $\mathrm{R} \& \mathrm{D}$ process $N L_{r}$ is time invariant since it is proportional to $g_{\lambda}$ [see (36)]. Therefore, total labor force employed in telecom goods production $N L_{x}$ is time invariant.

It has to be noted that the number of firms on a balanced growth path should be either time invariant or infinite. This follows from the elasticity of substitution between telecom goods perceived by a telecom firm,

$$
-e=\frac{\partial x}{\partial p_{x}} \frac{p_{x}}{x}=\frac{g_{x}}{g_{p_{x}}} .
$$

force employed in production $L_{x}$ and in R\&D $L_{r}$; and, finally, (v) using the profit function (9) with the market clearing condition (26). 
The perceived elasticity of substitution should be constant since $g_{x}$ and $g_{p_{x}}$ are constant on the balanced growth path. According to (22) or (23), the perceived elasticity of substitution is constant when either $N=$ const or $N=+\infty$. Moreover, according to (22) or (23), this elasticity is equal to $\varepsilon$ when $N=+\infty$.

From market clearing condition (24), the constraint (15), production technology of telecom goods (6), and the supply of a telecom good (17), it follows that

$$
N L_{x} \frac{1-\sigma}{b \sigma}=L_{Y}
$$

Given that on the balanced growth path $N L_{x}$ and $e$ are time invariant, the labor force employed in the production of the final goods $\left(L_{Y}\right)$ is time invariant.

From (56), (57), the labor market clearing condition (25), and the definition of R\&D process (7), it follows that

$$
r-\left(g_{w}-\delta g_{N}\right)=D\left(\xi L-g_{\lambda}\right),
$$

where D is given by (34). From the Euler equation it follows that

$$
r=\theta g_{C}+\rho,
$$

where $g_{C}$ is the growth rate of consumption.

From the budget constraint $\dot{A}=r A+w L-C$, equilibrium asset holdings $A=$ $V N$, entry condition $\dot{N}=\eta S$, a no arbitrage condition for a telecom firm $r V=\pi+\dot{V}$, $L=$ const, $V=$ const, $r=$ const, and (11), it follows that

$$
g_{C}=g_{Y}=g_{S}=g_{N}=g_{w}=g_{A}=g .
$$

In turn, the growth rate of final output, $g$, can be derived from the final goods production technology (3) together with the telecom goods production technology (6). It is given by $g=\psi g_{\lambda}$, where $\psi$ is given by (32). The growth rate in the telecommunications industry, $g_{\lambda}$, can be derived from (58) and (59). It is given by (34):

$$
g_{\lambda}=\frac{\xi D L-\rho}{(\theta-1+\delta) \psi+D} .
$$

Therefore, on the balanced growth path, the labor force allocations are given by (36)-(38).

The following parameter restrictions are required to hold in order to maintain 
standard regularity conditions, which guarantee positive growth:

$$
\varepsilon>1+\mu+\sigma, \xi D L>\rho .
$$

It is worth noting that when the number of firms is infinite, the growth rate of the final output is not a function of the number of firms since the perceived elasticity of substitution is equal to the actual one [i.e. the square brackets in (22) and (23) are zero].

\subsection{Online Appendix A.2}

There are two conditions which guarantee a stable equilibrium. The first condition is that the entry of firms reduces profits, equivalently the exit increases profits. The second condition is that the slope of the rate of return from (59) is steeper in $\left(r, g_{\lambda}\right)$ space than the same slope of the rate of return from (58). The latter condition implies that when $g_{\lambda}$ is smaller than the one which satisfies both (59) and (58), the required rate of return (59) is less than the actual rate of return (58). Therefore, there is an incentive to raise the $g_{\lambda}$ up to an equilibrium point where (59) and (58) are equal.

The first condition is automatically satisfied since $C M E$ is increasing and $Z P$ is declining with $N$. The second condition is satisfied if $\theta \geq 1$, which is a standard stability condition in multi-sector endogenous growth models. I assume that it holds.

\subsection{Online Appendix A.3}

When there are endogenous barriers to entry, the number of firms can be determined from the intersection of $C M E$ and $Z P$ curves, i.e.,

$$
\frac{\xi D L-\rho}{(\theta-1) \psi+D}=\frac{\rho}{e^{k}-1-(\theta-1) \psi}, k=C, B .
$$

From this equality it follows that

$$
e^{k}=\frac{\xi \sigma L[(\theta-1) \psi+1]}{\xi \sigma L-\rho}, k=C, B .
$$

Since the right-hand side of this expression does not depend on the type of competition, the growth of productivity in telecom goods production is the same under both types of competition. Therefore, the growth rate of the final output is the same under both types of competition. 
Under Cournot competition, the perceived elasticity of substitution is given by

$$
e^{C}=\frac{\varepsilon}{1+\frac{\varepsilon-1}{N}}
$$

Therefore, from (61) it follows that the number of firms is given by (41). Under Bertrand competition, the perceived elasticity of substitution is given by

$$
e^{B}=\varepsilon-\frac{\varepsilon-1}{N}
$$

which, together with (61), implies that the number of firms is given by (42).

In order to have positive number of firms, the following parameter restriction should hold:

$$
\xi \sigma L[\varepsilon-1-(\theta-1)(\sigma+\mu)]-\varepsilon \rho>0 .
$$

\subsection{Online Appendix B.1}

For brevity, I denote

$$
a_{1}=\frac{\varepsilon}{\varepsilon-1}(\sigma+\mu), a_{2}=\sigma+\mu, a_{3}=1-\sigma .
$$

From (3) it follows that $Y=N^{a_{1}} \lambda^{a_{2}} L_{x}^{a_{2}} L_{Y}^{a_{3}}$. The Social Planner's problem then is

$$
\begin{aligned}
& \max _{\left\{C, S, L_{x}, L_{r}\right\}}\left\{\int_{0}^{+\infty} \frac{C_{t}^{1-\theta}-1}{1-\theta} \exp (-\rho t) d t\right\} \\
& \text { s.t. } \\
& Y=C+S, \\
& Y=N^{a_{1}} \lambda^{a_{2}} L_{x}^{a_{2}} L_{Y}^{a_{3}}, \\
& L_{Y}=L-N\left(L_{x}+L_{r}\right), \\
& \dot{N}=\eta S, \\
& \dot{\lambda}=\xi N \lambda L_{r} .
\end{aligned}
$$

In terms of current value Hamiltonian, this problem is given by

$$
H_{S}=\max _{\left\{C, S, L_{x}, L_{r}\right\}}\left\{\frac{C^{1-\theta}-1}{1-\theta}+q_{Y}[Y-C-S]+q_{N} \eta S+q_{\lambda} \xi N \lambda L_{r}\right\},
$$

where the $q_{N}$ and $q_{\lambda}$ are the shadow values of increasing the number of firms and improving the productivity, respectively. The first order conditions and the state 
evolution laws are given by

$$
\begin{aligned}
& C^{-\theta}=q_{Y}, \\
& q_{Y}=\eta q_{N}, \\
& N L_{x}=\frac{a_{2}}{a_{3}} L_{Y}, \\
& q_{Y} a_{3} \frac{Y}{L_{Y}}=q_{\lambda} \xi \lambda, \\
& \dot{q}_{N}=\rho q_{N}-\frac{\partial H_{S}}{\partial N}, \\
& \dot{q}_{\lambda}=\rho q_{\lambda}-\frac{\partial H_{S}}{\partial \lambda} .
\end{aligned}
$$

From (64) and (69), it follows that

$$
N L_{x}=\frac{a_{2}}{a_{2}+a_{3}}\left(L-N L_{r}\right) .
$$

Equations (71) and (72) can be rewritten as

$$
\begin{aligned}
g_{q_{N}} & =\rho-\left\{\frac{q_{\lambda}}{q_{N}} \xi \lambda L_{r}+\frac{q_{Y}}{q_{N}}\left[a_{1} \frac{Y}{N}-a_{3} \frac{Y}{N}\left(\frac{L-L_{Y}}{L_{Y}}\right)\right]\right\}, \\
g_{q_{\lambda}} & =\rho-\left(\frac{q_{Y}}{q_{\lambda}} a_{2} \frac{Y}{\lambda}+\xi N L_{r}\right) .
\end{aligned}
$$

From (70), (75), and (69), it follows that

$$
g_{q_{\lambda}}=\rho-\left(\frac{a_{2}}{a_{2}+a_{3}} \xi L+\frac{a_{3}}{a_{2}+a_{3}} \xi N L_{r}\right) .
$$

From (66), (70) and (67), it follows that

$$
-\theta g+g_{Y}-g_{L_{Y}}=\rho-\frac{a_{2}}{a_{2}+a_{3}}\left(\xi L-g_{\lambda}\right) .
$$

Given that the labor allocations are constant, from (62) and (76), it follows that

$$
(\theta-1) g+\rho=\frac{a_{2}}{a_{2}+a_{3}}\left(\xi L-g_{\lambda}\right) .
$$

In turn, from (63), (65), and (62), it follows that

$$
g=\frac{a_{2}}{1-\left(a_{1}-a_{2}\right)} g_{\lambda},
$$


where $1-\left(a_{1}-a_{2}\right)=\frac{\varepsilon-1-(\sigma+\mu)}{\varepsilon-1}$ should be greater than zero. I denote

$$
\begin{aligned}
D^{S} & =\frac{a_{2}}{a_{2}+a_{3}}=\frac{\sigma+\mu}{1+\mu} \\
\psi^{S} & =\frac{a_{2}}{1-\left(a_{1}-a_{2}\right)}=\frac{(\varepsilon-1)(\sigma+\mu)}{\varepsilon-1-(\sigma+\mu)} .
\end{aligned}
$$

From (77) and (78), it follows that $g_{\lambda}$ is given by (45), and $g=\psi^{S} g_{\lambda}$. I denote these growth rates by $g^{S}$ and $g_{\lambda}^{S}$ respectively. In addition to $\varepsilon>1+\sigma+\mu$, a parameter restriction is $\xi D^{S} L-\rho>0$, which is automatically satisfied if $\xi D L-\rho>0$. The optimal conditions (67) and (68) suggest that in the social optimum there is permanent entry. Meanwhile, the socially optimal labor allocations are given by (47)-(49).

\subsection{Online Appendix B.2}

The growth rates of the productivity in telecom goods production in the social optimum and in the decentralized equilibrium are given by

$$
\begin{aligned}
g_{\lambda}^{S} & =\frac{\xi D^{S} L-\rho}{(\theta-1) \psi^{S}+D^{S}}, \\
g_{\lambda} & =\frac{\xi D L-\rho}{(\theta-1+\delta) \psi+D},
\end{aligned}
$$

respectively. Comparison of these growth rates is equivalent to comparison of the following expression with zero:

$$
\begin{aligned}
& \xi L\left[(\theta-1) \psi^{S} D-(\theta-1+\delta) \psi D^{S}\right] \\
& +\rho\left[(\theta-1+\delta) \psi+D-(\theta-1) \psi^{S}-D^{S}\right] .
\end{aligned}
$$

\section{Entry in the Decentralized Equilibrium}

Since in this case $\psi=\psi^{S}$, the comparison of (79) with zero is equivalent to

$$
\psi\left[D-D^{S}\right](\xi L \theta+\rho)-\psi(\xi D L-\rho) * 0 .
$$

The parameter restriction $\xi D L-\rho>0$ and

$$
D \leq \sigma \leq \frac{\sigma+\mu}{1+\mu}=D^{S}
$$


imply that the socially optimal growth rate is higher than the decentralized equilibrium one: $g_{\lambda} \leq g_{\lambda}^{S}$.

\section{No Entry in the Decentralized Equilibrium}

It can be shown that $\frac{\partial D}{\partial N}>0$ and $\frac{\partial g_{\lambda}}{\partial D}>0$; therefore, it is sufficient to take $N=+\infty$ if interested in $g_{\lambda} \leq g_{\lambda}^{S}$. According to (79), when $N=+\infty$, there is no entry in the decentralized equilibrium, and $g_{\lambda} \leq g_{\lambda}^{S}$, the following holds

$$
\begin{aligned}
& 0 \geq \\
& \xi L(\theta-1)\left[\frac{(\mu+\sigma)(\varepsilon-1)}{\varepsilon-1-(\mu+\sigma)} \frac{\varepsilon-1}{\varepsilon-\sigma} \sigma-(\sigma+\mu) \frac{\sigma+\mu}{1+\mu}\right] \\
& +\rho\left\{(\theta-1)\left[-\frac{(\mu+\sigma)^{2}}{\varepsilon-1-(\mu+\sigma)}\right]+\frac{\varepsilon-1}{\varepsilon-\sigma} \sigma-\frac{\sigma+\mu}{1+\mu}\right\} .
\end{aligned}
$$

Given that $(\sigma+\mu) /(1+\mu) \geq \sigma$, a sufficient condition for $g_{\lambda} \leq g_{\lambda}^{S}$ is

$$
\begin{aligned}
& 0 \geq \\
& \xi L(\theta-1) \sigma(\mu+\sigma)\left[\frac{(\varepsilon-1)^{2}-(\varepsilon-\sigma)(\varepsilon-1-(\mu+\sigma))}{(\varepsilon-1-(\mu+\sigma))(\varepsilon-\sigma)}\right] \\
& +\rho\left\{(\theta-1)\left[-\frac{(\mu+\sigma)^{2}}{\varepsilon-1-(\mu+\sigma)}\right]+\frac{\varepsilon-1}{\varepsilon-\sigma} \sigma-\frac{\sigma+\mu}{1+\mu}\right\} .
\end{aligned}
$$

The second bracket is always negative; therefore, for $g_{\lambda} \leq g_{\lambda}^{S}$ it is sufficient to have

$$
(\varepsilon-1)^{2}-(\varepsilon-\sigma)[\varepsilon-1-(\mu+\sigma)] \leq 0
$$

or equivalently

$$
\varepsilon \geq \frac{1-\sigma(1+\mu+\sigma)}{1-\mu-2 \sigma}
$$

The last ratio increases with $\sigma$; therefore, it would be sufficient if the inequality holds when $\sigma \approx 1$. When $\sigma \approx 1$, this ratio is equal to unity, and under the parameter restriction $\varepsilon>1+\mu+\sigma$, the inequality always holds. Therefore, the socially optimal growth rate of the productivity in telecom goods production is always higher than the one in the decentralized equilibrium: $g_{\lambda} \leq g_{\lambda}^{S}$. 


\subsection{Online Appendix B.3}

\section{Entry in the Decentralized Equilibrium}

Given that $g_{\lambda} \leq g_{\lambda}^{S}$, the following is true:

$$
N L_{r}=\frac{g_{\lambda}}{\xi} \leq \frac{g_{\lambda}^{S}}{\xi}=N L_{r}^{S}
$$

In turn, from (56) and (73) follows that

$$
\begin{aligned}
N L_{x} & =\frac{1}{\xi}(\theta g+\rho), \\
N L_{x}^{S} & =\frac{1}{\xi}\left[(\theta-1) g^{S}+\rho\right] .
\end{aligned}
$$

Therefore, the comparison of $N L_{x}$ and $N L_{x}^{S}$ is equivalent to the comparison of

$$
\theta g *(\theta-1) g^{S}
$$

When $\theta$ is close to $1, N L_{x}>N L_{x}^{S}$. However, when $\theta$ is sufficiently high, $N L_{x}<N L_{x}^{S}$ since $g_{\lambda}<g_{\lambda}^{S}$.

\section{No Entry in the Decentralized Equilibrium}

From (56) and (73), it follows that

$$
\begin{aligned}
N L_{x} & =\frac{1}{\xi}[(\theta-1) g+\rho], \\
N L_{x}^{S} & =\frac{1}{\xi}\left[(\theta-1) g^{S}+\rho\right] .
\end{aligned}
$$

Given that $g \leq g^{S}$ it follows that

$$
N L_{x} \leq N L_{x}^{S}
$$

In turn, given that $g_{\lambda} \leq g_{\lambda}^{S}$, the following holds

$$
N L_{r} \leq N L_{r}^{S}
$$

When there are exogenous barriers to entry, the growth rate of productivity in telecom goods production $g_{\lambda}$ and the growth rate of the final output $g$ increase with the number of firms $N$ and with the toughness of competition. Therefore, $N L_{x}$ and $N L_{r}$ increase with $N$ and toughness of competition. This means that as $N$ increases 
and/or the competition becomes tougher, $N L_{x}$ tends to $N L_{x}^{S}$, and $N L_{r}$ tends to $N L_{r}^{S}$.

\subsection{Online Appendix C}

In this section I derive a policy which delivers the socially optimal allocations as a decentralized equilibrium outcome on balanced growth path. The policy subsidizes demand for telecom goods $\left(\tau_{x}\right)$, it subsidizes telecom firms' R\&D so that the returns do not decline with entry $\left(\tau_{\lambda}\right)$ and makes transfers to the firm so that to guarantee that the profits of any telecom firm are non-negative $\left(T_{\pi}\right)$. This policy is financed by lump-sum tax $T$ imposed on the household.

Under this policy the demand for telecom goods and telecom firm $j$ 's problem are

$$
\begin{aligned}
& x_{j}=X\left[\frac{P_{X}}{\left(1-\tau_{x}\right) p_{x_{j}}}\right]^{\varepsilon}, \\
& P_{X} X=\left(1-\tau_{x}\right) \sum_{j=1}^{N} p_{x_{j}} x_{j},
\end{aligned}
$$

and

$$
\begin{aligned}
& V_{j}(t)=\max _{\left\{L_{x_{j}}, L_{r_{j}}, u_{j, i}, u_{i, j}\right\}}\left\{\int_{t}^{+\infty} \hat{\pi}_{j}(\tilde{t}) \exp \left[-\int_{t}^{\tilde{t}} r(s) d s\right] d \tilde{t}\right\} \\
& \text { s.t. } \\
& \hat{\pi}_{j}=\pi_{j} \sum_{i=1, i \neq j i=1, i \neq j}^{N} \sum^{N}+\tau_{\lambda} p_{\lambda_{j}} \lambda_{j}+T_{\pi}, \\
& (6),(7),(9) .
\end{aligned}
$$

Let a symmetric equilibrium hold. The optimal rules can be derived as in the decentralized equilibrium. The lump-sum tax imposed on the household then is given by

$$
T=N\left(\tau_{x} p_{x} x+\tau_{\lambda} p_{\lambda} \lambda+T_{\pi}\right)
$$

\section{Balanced Growth Path}

As in the decentralized equilibrium without policy, it can be shown that

$$
g^{G O}=\psi g_{\lambda}^{G O}
$$


where $g^{G O}$ is the growth rate of the final output and $g_{\lambda}^{G O}$ is the growth rate of productivity, which is given by

$$
g_{\lambda}^{G O}=\frac{\xi D^{G O} L-\rho}{(\theta-1) \psi+D^{G O}+\psi-\alpha \frac{\tau_{\lambda}}{N}},
$$

where

$$
D^{G O}=\left[\left(1-\tau_{x}\right) \frac{1-\sigma}{b \sigma}+1\right]^{-1} .
$$

Moreover, similarly it can be shown that

$$
\begin{aligned}
& \xi N L_{r}=g_{\lambda}^{G O}, \\
& N L_{r}=\frac{g_{\lambda}^{G O}}{r-\left(g_{w}-g_{N}+g_{\lambda}^{G O} \alpha \frac{\tau_{\lambda}}{N}\right)} N L_{x}, \\
& N L_{x}\left(1-\tau_{x}\right) \frac{1-\sigma}{b \sigma}=L_{Y} .
\end{aligned}
$$

In order to have socially optimal allocations and growth rates, the policy should make sure that

$$
\begin{aligned}
g_{\lambda}^{G O} & =g_{\lambda}^{S}, \\
N L_{x} & =N L_{x}^{S} \Leftrightarrow D^{G O}=D^{S} \text { and } g_{\lambda}^{G O}=g_{\lambda}^{S},
\end{aligned}
$$

and

$$
T_{\pi}: \pi=\frac{\theta}{\eta}\left(g^{S}+\rho\right) .
$$

In order to have $D^{G O}=D^{S}$, I set

$$
\tau_{x}=1-\frac{\sigma}{\sigma+\mu} b
$$

Such a policy corrects the ratio of $N L_{x}$ to $L_{Y}$. In order to correct also the ratio of $N L_{r}$ to $N L_{x}$ let

$$
\tau_{\lambda}=\frac{N}{\alpha} \psi
$$

Moreover, in order to have $\pi=\frac{\theta}{\eta}\left(g^{S}+\rho\right)$, I set

$$
T_{\pi}=w L_{x} \tau_{\pi}
$$

In such a case, given that the labor force allocations should be socially optimal the 
profit of a telecom firm is

$$
\pi=\frac{w}{N} N L_{x}^{S}\left[\frac{1}{e-1}+\left(\psi^{S}-1\right) \frac{N L_{r}^{S}}{N L_{x}^{S}}+\tau_{\pi}\right]
$$

Therefore, the rate of transfer, $\tau_{\pi}$, is such that:

$$
\pi=\frac{\theta}{\eta}\left(g^{S}+\rho\right)
$$

When $\psi^{S} \approx 1$ and $\varepsilon$ is small the transfer can be negative $\tau_{\pi}<0$. Meanwhile, if $\varepsilon$ is very large number and $B^{S}<1$ then the transfer can be positive $\tau_{\pi}>0$.

Under this policy there is permanent entry, therefore,

$$
\begin{aligned}
& g^{G O}=g^{S}, \\
& g_{\lambda}^{G O}=g_{\lambda}^{S}, \\
& N L_{r}^{G O}=N L_{r}^{S}, \\
& N L_{x}^{G O}=N L_{x}^{S}, \\
& L_{Y}^{G O}=L_{Y}^{S} .
\end{aligned}
$$

\subsection{Online Appendix D}

Many countries have implemented policies deregulating entry into the telecommunications industry and privatizing state owned companies. These changes have commonly resulted in significant changes in the market structure of the telecommunications industry. Table 1 illustrates the changes in the number of medium and large telecom firms in France, Germany, the UK, and the US over the period 1995-2007. Medium size firms have 50-249 employees and large firms have more than 250. The telecommunications industry is defined as 642 in ISIC Rev. 3 codes.

In sum, telecommunications markets have become less concentrated. These changes entail growth and welfare effect according to the theoretical model presented in this paper. 


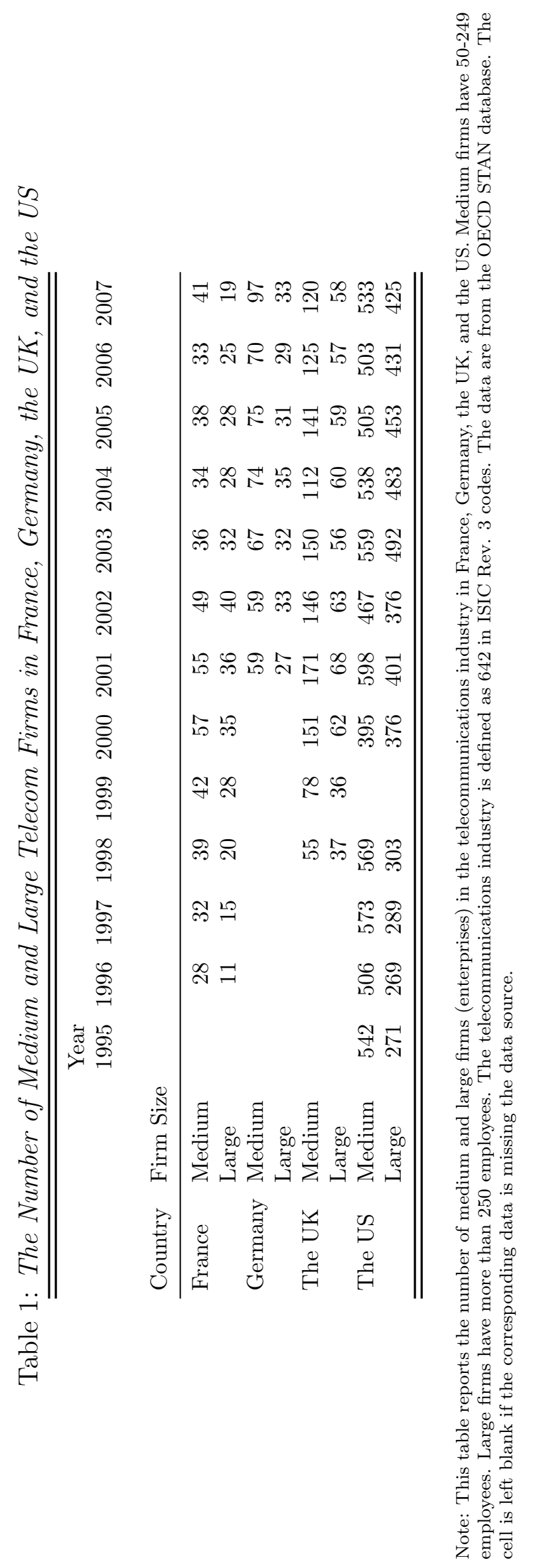

